\title{
EFFECT OF FUEL INJECTION PRESSURE, TIMING AND COMPRESSION RATIO ON PERFORMANCE AND EMISSION CHARACTERISTICS OF FISH-OIL OPERATED DIESEL ENGINE
}

\author{
Keerthi Kumar N ${ }^{1}$, B Yogesh ${ }^{2}$, Shankar Nag G L ${ }^{3}$ \\ ${ }^{1}$ Assistant Professor, Mechanical Engineering Department, BMS Institute of Technology \& Mgmt, Bangalore, \\ Karnataka, India \\ ${ }^{2}$ Assistant Professor, Mechanical Engineering Department, PNS Institute of Technology, Bangalore, Karnataka, \\ India \\ ${ }^{3}$ Assistant Professor, Mechanical Engineering Department, Sri Siddhartha Institute of Technology, Tumkur,
} Karnataka, India

\begin{abstract}
The demand of resources and fuels for the technologies development is increasing day by day. As the conventional sources of energy are depleting, various methods had to be developed to meet the demand and also to reduce emissions. Hence, alternative sources of energy and newer combustion technology are needed to develop to meet both acceptable engine performance and emission norms. Biofuels are one among those whose energy is derived from carbon fixation. In this context, Extracted oil from wastes of marine resources has been selected as a source of raw resources for creation of biodiesel, which plays an important role for above said need. In the present work, biodiesel is prepared from fish oil is selected and various performance and emission characteristics namely BSFC, BTE, CO, HC and $N O_{x}$ were compared with commercially available diesel for an compression ratio of 17.1:1 and 20.1:1, different blends of $B 20, B 30$ with different injection pressure and injection timing of 250, 300 bar and STD $\left(20.5^{\circ}\right)$ respectively. The BTE has found to be more in biodiesel B 20, B 30 than diesel at CR 17.5 and injection pressure of 250 bar, almost same efficiency has been observed for injection pressure of 300 bar. HC emission from diesel fuel has given more as compare to B 20 for CR17.5 and Injection pressure of 300 bar. CO emissions are also found to be less for $B 20$ at same injection pressure and compression ratio. Because of high oxygen content in fish oil there is an increase in $N O_{x}$ emission as compare to Diesel fuel. But coming for BSFC, biodiesel shows almost same values as that of conventional diesel for all injection pressure and compression ratio. Finally cost estimation has also been done by considering all the materials required, processing cost and by product cost to produce biodiesel from fish oil and it is observed that, cost of fish oil biodiesel is less which is acceptable and appreciable as compared to conventional diesel.
\end{abstract}

Keywords: Biodiesel, Fish Oil, Injection Pressure, Compression Ratio and Emissions.

\section{INTRODUCTION}

The most significant source of hazardous pollutants is increased population, development in technology, higher living standards and industrialization has lead to intricate situation of energy supply. The fossil fuel has been considered as major conventional source of energy since there invention. The worldwide demand for energy is also growing at faster rate leading to faster depletion of fossil fuel with increase of global warming. Fossil fuels are presently the major source of $\mathrm{CO}_{2}$ emissions and their combustion is contributing major source of hazard to clean environment. Because of the depletion of reserves of fossil fuel, and stringent government regulations about emissions, studies towards some alternative, renewable, complete combustion and clean energy sources have gained much importance now a days.

Hence, the fluids like waste vegetable oils, oils from industrial waste and waste animal fat after transesterification is considered as proper alternative due to their prevalent fuel properties. From the literature it is clear that, biodiesel produced from Jatropha curcas (Ratabgyit), Pongamia Pinnata (Karanji), Palm, Canola, Mahua (Madhuca Indica) and animal waste etc., are environment-friendly and also renewable alternative fuel that can be widely used as alternate source of fuel in internal combustion engines. [10, $11,18,19$,

Further, vegetable and animal fats are classified as edible and nonedible oils. Generally, biodiesels produced from edible oils will contain low free fatty acids and hence oil produced will be higher in cost. Hence, it is concluded not to use edible oil as a fuel. According to Atabani A E. et, al and many more, the use of non-edible oils for the production of biodiesel can considerably reduce the cost of biodiesel. Hence it can be concluded that, the most appropriate feed stocks for biodiesel production are waste non edible oils [14, $15,16,17]$.

Edwin [1], experiments were conducted on diesel engines using fish oil for various blends and found break thermal 
efficiency is high with diesel and small decrease of $0.599 \%$ for B20 with $80 \%$ load. Because of pre combustion exhaust temperature is lower.

Ken Araya et al. [2] converted sunflower oil and fish oil to their methyl esters, and experiments were conducted on single cylinder diesel engine, the results obtained as 0.11 $\mathrm{kW}$ more power output for $3 \%$.

Hulya et al. [3] analyzed both qualitatively and quantitatively using chromatography. The different percentages of fatty acids were detected in various oils.

The experiment carried out by J.F. Costa. et al. [4] was on oil extracted from fish canning industry waste and experiment focused on pre treatment and reaction and evaluated the control of acid catalyst concentration in the esterifacation process. Form the results, it is found that the yield and quality of product is majorly dependent on catalyst concentration

S. Godiganur et al. [5] conducted experiments for various blends and various biodiesel oil and found the maximum thermal efficiency of $31.74 \%$ for B20 and it is higher that neat diesel fuel.The brake thermal efficiency obtained for all blend percentage were less than that of diesel.

In the study of Recep Yumrutas et al. [6] the performance and emission of two fuels called as Fish and Cooking oil Methyl Ester for blend of $25 \%$ on volume basis is studied and concluded as the fish oil gave improved performance and reduced emission than that of Cooking oil except $\mathrm{NO}_{\mathrm{X}}$ and it is reached upto $17.2 \%$ where as BSFC increased upto $5.69 \%$.

Cherung-Yuan Lin et al. [7] produced biodiesel using discarded parts of marine fish species using $\mathrm{NaOH}$ as alkali catalyst as a biofuel. The results were showed that fish oil biodiesel can be used as an alternate fuel without much modification of engine.

Rasim Behcet et al. [8] blended fish oil with diesel with a ratio of $25 \%: 75 \%, 50 \%: 50 \%, 75 \%: 25 \%$. The test was conducted at maximum load with various speeds. As a result, it has found that there has been a decrease with $4.14 \%$ in fish oil methyl ester and its blends, $5.16 \%$ reduction in power, while $4.96 \%$ increase was observed at SFC on the other hand $4.576 \%, 21.3 \%$ and $33.42 \%$ reduction were recorded in $\mathrm{CO}_{2}, \mathrm{CO}, \mathrm{HC}$ respectively.

GVNSR Ratnakar Rao et al. [9] was conducted experiments on 7 variable compression ratios in CI engine using mahua oil as fuel. At standard test conditions best result were found at 15.7 compression ratio in all the aspects

Cherng- Yuan Lin uses biodiesel produced from various source like Vegetable, animal fat, algae and concluded as all the biofuels produced from above can be an outstanding alternative fuel to diesel.
From the literature it can be concluded that, there is a need to find out the alternative feed stocks for producing the biodiesel, which can full fill the ASTM standards and also there is a need to increase the efficiency and to decreases exhaust emissions of the engine using bio-diesel as fuel.

In this research paper we used biodiesel produces from fish oil, for determining the combustion and emission characteristics and found good and promising results when compared for neat diesel fuel. Various experiments have been done for both the fuel for different injection pressure and different compression ratio of 17.1:1 and 20.1:1.

\section{EXPERIMENTAL}

\subsection{Fuel Properties}

Transisterification process is done to convert raw fish oil into biodiesel. The bio-diesel produced by the process of transesterification has much lower viscosity, no suspended matter, and colour was transparent, light yellow which makes it capable of replacing petroleum diesel in diesel engines. The desired properties for fish oil biodiesel have been achieved and it is as shown in table. The conversion process of fish oil to pure biodiesel is shown if figure 1 .

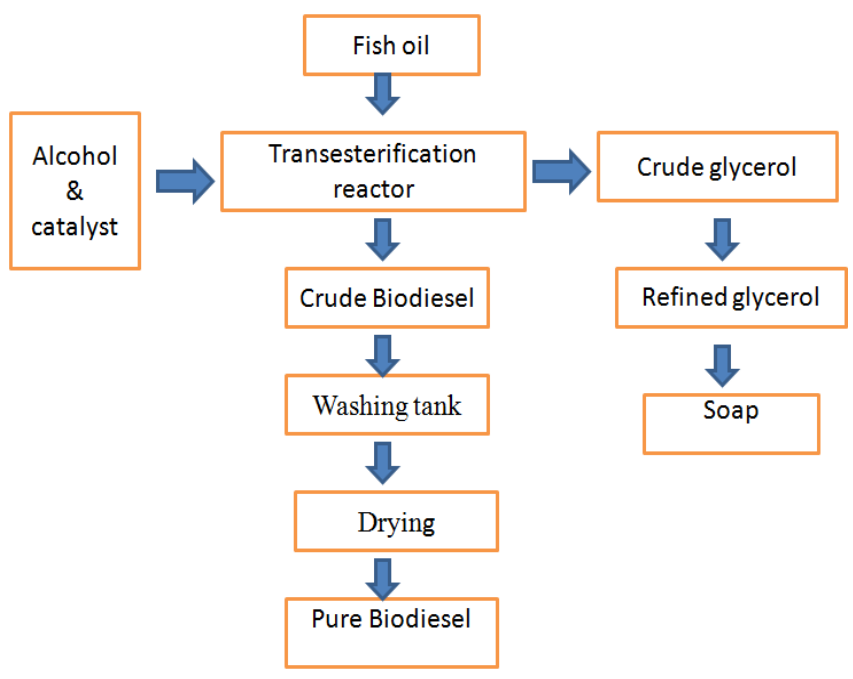

Fig -1: Transesterification Process flow chart

Table -1 : Properties of pure diesel and biodiesel (fish oil)

\begin{tabular}{lll}
\hline Property & $\begin{array}{l}\text { Pure } \\
\text { Diesel }\end{array}$ & $\begin{array}{l}\text { Fish oil } \\
\text { Biodiesel }\end{array}$ \\
\hline Density $\left(\mathrm{kg} / \mathrm{m}^{3}\right)$ & 830 & 875 \\
Flash point ${ }^{0} \mathrm{C}$ & 54 & 165 \\
Fire point ${ }^{\circ} \mathrm{C}$ & 59 & 174 \\
Kinematic viscosity at $40^{\circ} \mathrm{C}\left(\mathrm{mm}^{2} / \mathrm{s}\right)$ & 2.3 & 4.3 \\
Calorific value $(\mathrm{KJ} / \mathrm{kg})$ & 42,800 & $44,216.71$ \\
Oxygen Content & Nil & $10.9 \%$ \\
\hline
\end{tabular}

\subsection{Experimental Setup}

Fish oil methyl ester blends and pure diesel were used to test a Kirloskar, single cylinder, 4-stroke, water-cooled direct injection diesel engine having a maximum power output of $5.2 \mathrm{~kW}$ at $1500 \mathrm{rpm}$, compression ratio of 17.5:1, 20.1:1. The engine was coupled with an eddy current dynamometer to apply different engine loads. The performance and 
emission characteristics were studied at different engine loads, different blends and different operating conditions. Various emissions like carbon monoxide (CO), Hydrocarbon ( $\mathrm{HC})$, Nitrous oxide $\left(\mathrm{NO}_{\mathrm{x}}\right)$ and carbon dioxide $\left(\mathrm{CO}_{2}\right)$ were measured using an exhaust gas analyzer. The line diagram of experimental set-up and photographic views of engine are as shown in Fig 2 and 3 respectively. The specification of the engine and generator is shown in Table 2.

Table -2 : Engine Specifications used for testing

\begin{tabular}{ll}
\hline Engine Parameters & Specifications \\
\hline Engine & TV1(Kirloskar, Four Stroke single \\
& cylinder with 7 HP at 1500 rpm) \\
Bore Diameter & $87.5 \mathrm{~mm}$ \\
Stroke Length & $110 \mathrm{~mm}$ \\
Capacity & $661 \mathrm{cc}$ \\
Cr & $17.5: 1 \& 20.1: 1$ \\
Dynamometer & Eddy Current dynamomete \\
Fuel injection Pressure & 250bar \& 300bar \\
Cylinder Pressure & Piezo-Sensor, range 2000 \\
Fuel Injection Pressure & Piezo Sensor, range 5000 \\
\hline
\end{tabular}

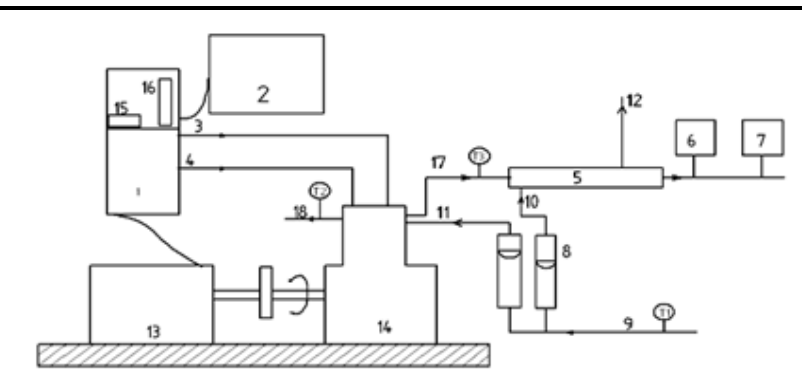

1. Control Panel, 2.Computer system, 3.Diesel flow line, 4.Air flow line, 5.Calorimeter, 6.Exhaust gas analyzer, 7.Smoke meter, 8.Rota meter, 9\&11.Inlet water temperature, 13.Dynamometer, 14.CI Engine, 15.Speed measurement, 10. Calorimeter inlet water temperature, 12.Calorimeter outlet water temperature, 16.Burette for fuel measurement, 17.Exhaust gas outlet, 18. Outlet water temperature, T1.Inlet water temperature, T2. Outlet water temperature, T3.Exhaust gas temperature.

Fig -2: Line diagram and its different parts

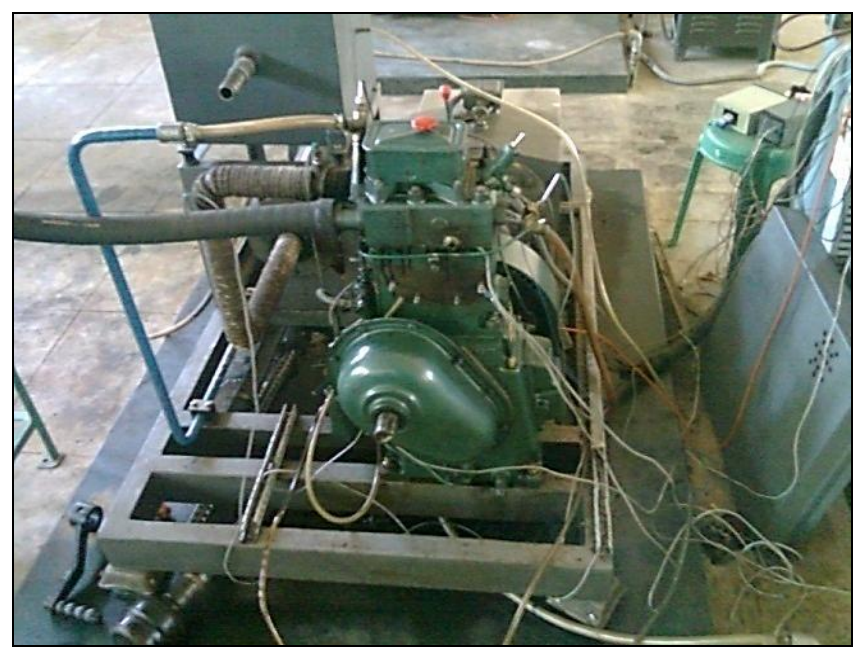

Fig -3: Experimental Setup

\subsection{Experimental Procedure}

Various experiments were conducted on TV1, Kirloskar diesel engine using neat diesel and fish oil biodiesel blends at $1500 \mathrm{rpm}$. Initially Performance and emission tests were conducted only for neat diesel oil with standard operating conditions, later tests were conducted for various biodiesel blends in order to optimize the blends concentration. Blending of diesel and fish oil is done by volume basis by varing the concentration form 0 to $60 \%$. The optimum blend ratio was found out based on thermal efficiency. Finally it is optimized that B20 and B30 is best suited.

The above said blends were then tested for two injection pressure of 250 and 300 bar and also by changing compression ratio of 17.5 and 20.1. The performance and emission data was then analyzed, power output, fuel consumption, specific fuel consumption, thermal efficiency ect., for both blends. To measure the pollutants from exhaust, gas analyzer was used.

\section{RESULTS}

\subsection{Engine performance}

Performance of the engine with Fish oil biodiesel of B-20, B-30 and for neat diesel was evaluated in terms of brake specific fuel consumption, brake specific fuel consumption, thermal efficiency and exhaust emissions at different compression ratio and injection pressure.

\subsection{Break Specific Fuel Consumption}

The Break Specific Fuel Consumption obtained from the test for different fuel blends (B20, B30 and neat diesel) and different injection pressure of 250 and 300 bar at compression ratio of $17.5 \& 20.1: 1$ at injection timing STD $20.5^{0}$ is as shown in chart $1,2,3$ and 4 respectively.

From the chart1, 2, 3 and 4 it is found that, BSFC decreases for all kind of fuel blends as the load increases, and it is found that SFC for blend of B30 is quit good for compression ratio 20.1, injection pressure 300 bar and 250 bar even though the results obtained are very close to each other and with the diesel fuel also. Hence we conclude that B30 will give better results with less specific fuel consumption even for higher loads. It is due to the truth that engine consumes more fuel with bio-diesel blend fuels than with neat diesel fuel to produce the same output due to the calorific value. From literature also it was observed the same nature for other fuel like karanja, mahua and honge oils [17].

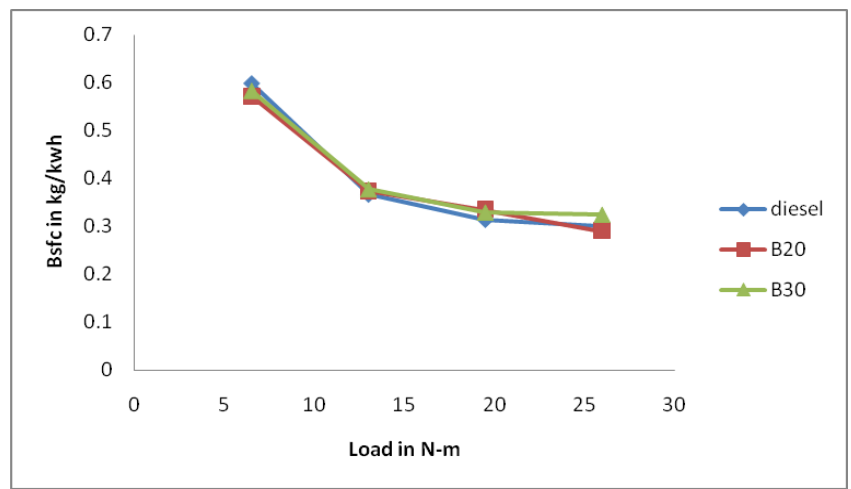

Chart -1: $\mathrm{BSFC}$ v/s Load for CR - 17.5, IP = 250 bar. 


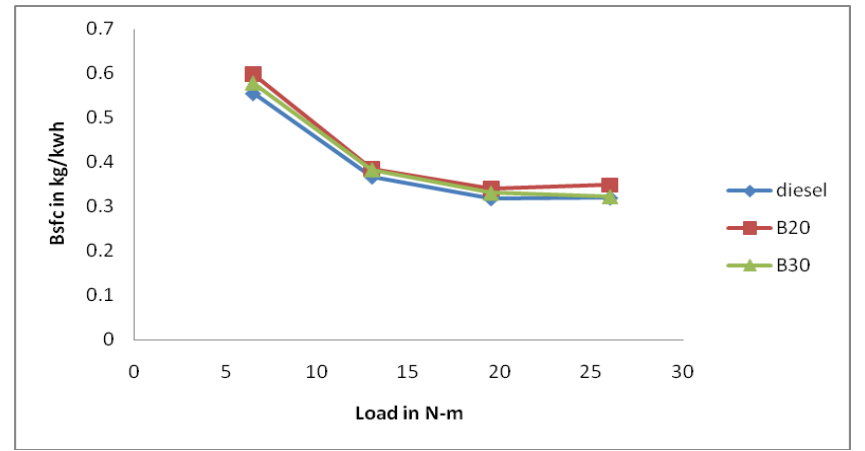

Chart -2: BSFC v/s Load for CR-17.5, IP=300 bar.

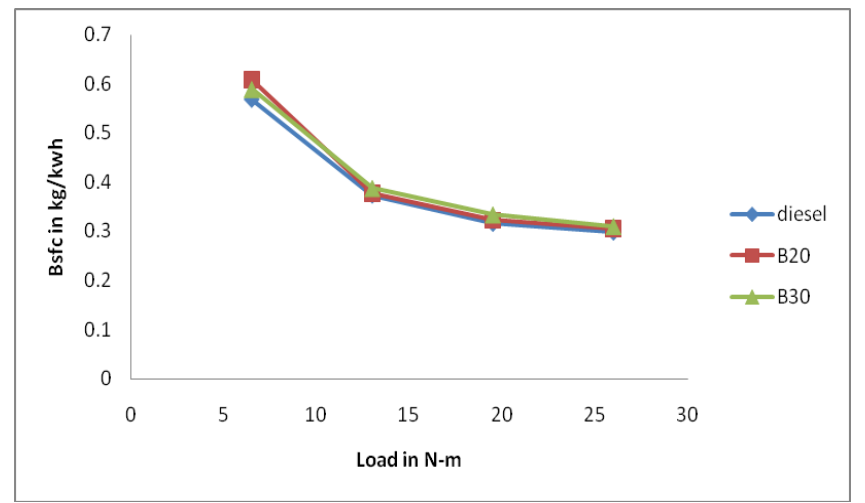

Chart -3:: BSFC v/s Load for $\mathrm{CR}=20.1, \mathrm{IP}=250$ bar.

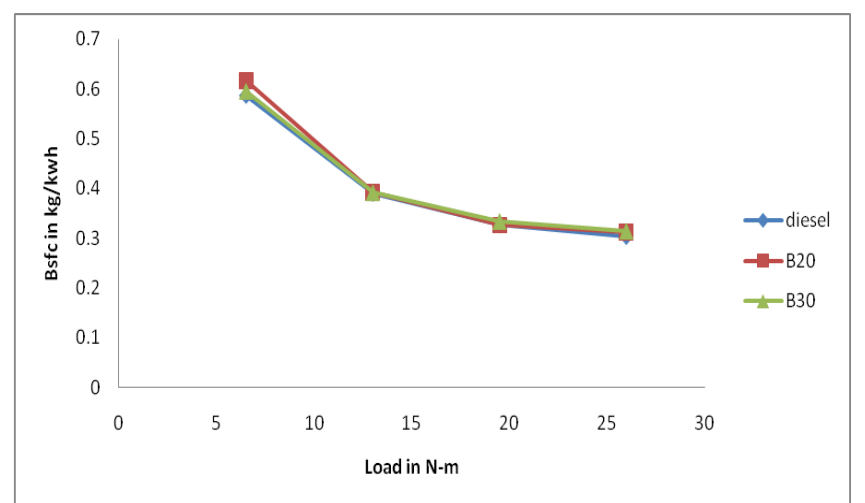

Chart -4: BSFC v/s Load for $\mathrm{CR}=20.1$, IP=300 bar.

\subsection{Break Thermal Efficiency}

The Deviation of Brake Thermal efficiency for compression ratio 17.5 and 20.1, injection pressure of 250 bar, 300 bar with injection timing of STD $20.5^{0}$ for different fuels blends are shown in chart 5,6,7,8 respectively. From the nature of graph it is observed that, break thermal efficiency increases as the load increases and it is true for all the blends and for both injection pressure. This is due to decrease in loss of heat and increase in power output with increase in load. BTE for bio-diesel in comparison to diesel is a better option for part load. The maximum efficiency is obtained for at a load of $25 \mathrm{~N}-\mathrm{m}$ for all the fuels, B30 gave (26.32\%) was slightly less than that of diesel $(26.48 \%)$ for the $\mathrm{CR}=17.5$ \& IP=300bar. This lower brake thermal efficiency obtained may be due to reduction in calorific value the results obtained are almost equal due to close calorific value for diesel and B30 blend. The reduction in brake thermal efficiency is due to increased fuel consumption in blend
(B30). Better results are obtained for $\mathrm{IP}=300 \mathrm{bar}$. Based on the obtained results it is concluded that the performance of the engine with biodiesel blends can be easily compared to that with diesel, in terms of brake thermal efficiency. Hence, B-30can be concluded as a better fuel blend

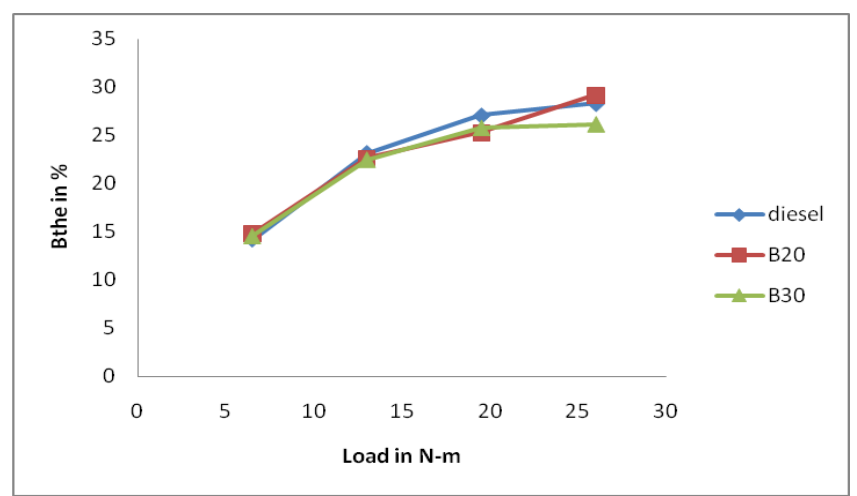

Chart -5: BTE v/s load for $\mathrm{CR}=17.5, \mathrm{IP}=250$ bar.

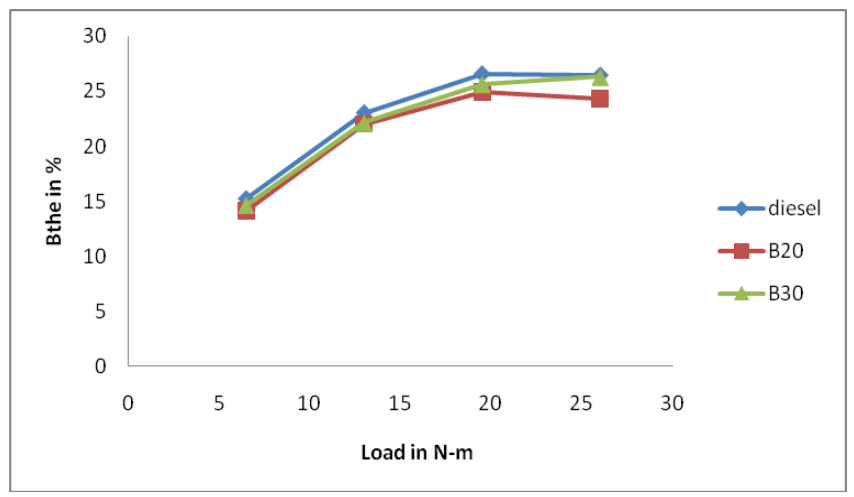

Chart -6:: BTE v/s load for $\mathrm{CR}=17.5$, IP=300 bar.

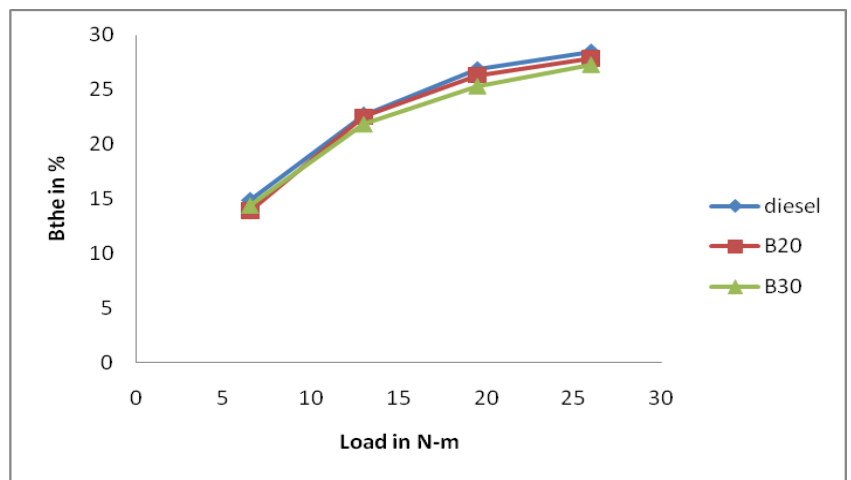

Chart -7: BTE v/s load for $\mathrm{CR}=20.1$, IP=250 bar.

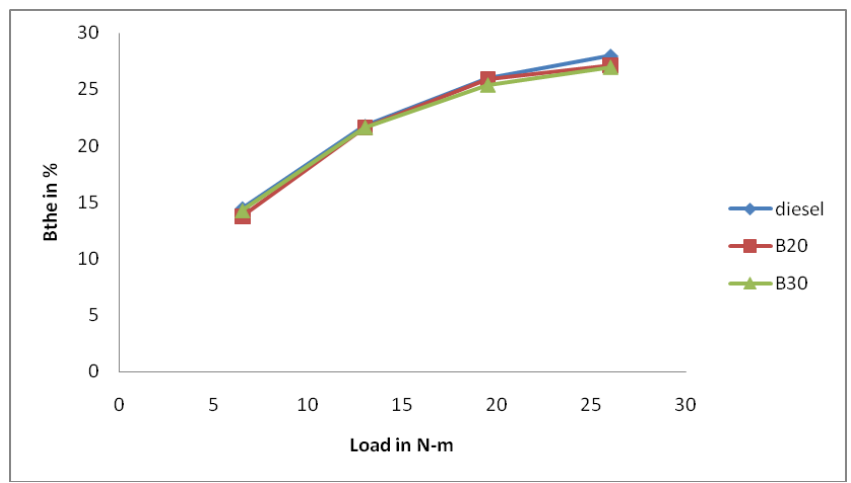

Chart -8: $\mathrm{BTE}$ v/s load for $\mathrm{CR}=20.1, \mathrm{IP}=300 \mathrm{bar}$. 


\subsection{Carbon Monoxide}

Chart 9,10,11,12 shows the levels of CO emissions for different loading conditions for neat diesel and different biodiesel at compression ratio of 17.5:1, 20.1:1 and injection pressure of 250bar and 300bar respectively. Generally Carbon Monoxide is generated because of in complete combustion and it is the byproduct of CO. this happens in an engine when misfire occurs. From the charts is clear that, bio-diesel blends are showing less carbon monoxide as compared to neat diesel due to complete combustion at higher injection pressure IP=300bar. As the blend percentage increases, the formation of carbon monoxide decreases. This is due to complete oxidation of bio-diesels.. At $26 \mathrm{~N}-\mathrm{m}$ load for IP=300bar, blend $\mathrm{B} 30$ gives less $\mathrm{CO}$ emissions as compared other bends.

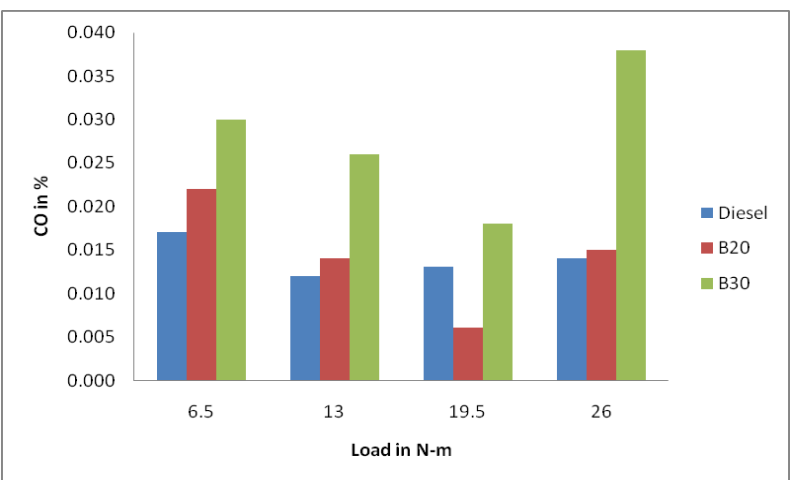

Chart -9: Load v/s Carbon monoxide for $\mathrm{CR}=17.5$, $\mathrm{IP}=250 \mathrm{bar}$.

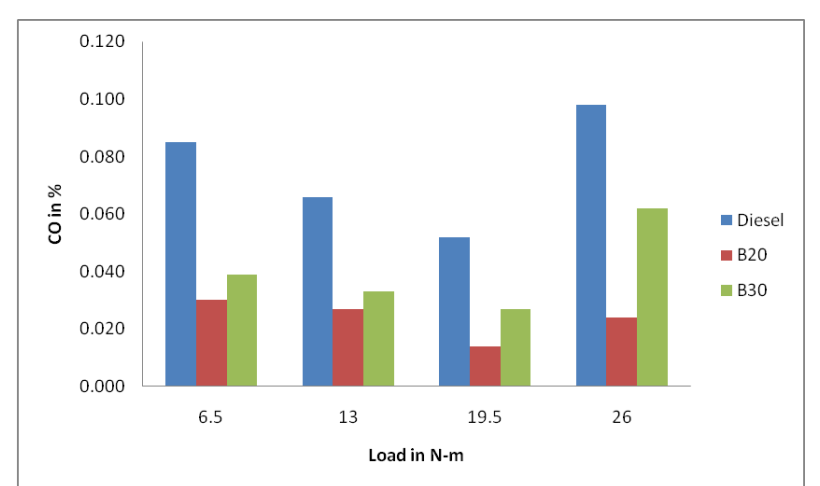

Chart -10: Load v/s Carbon monoxide for $\mathrm{CR}=17.5$, $\mathrm{IP}=300 \mathrm{bar}$.

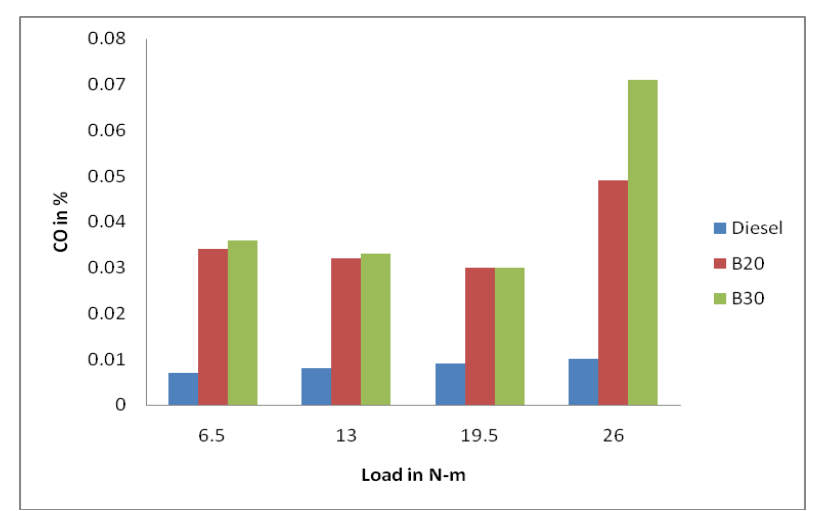

Chart -11: Load v/s Carbon monoxide for $C R=20.1$, $\mathrm{IP}=250 \mathrm{bar}$.

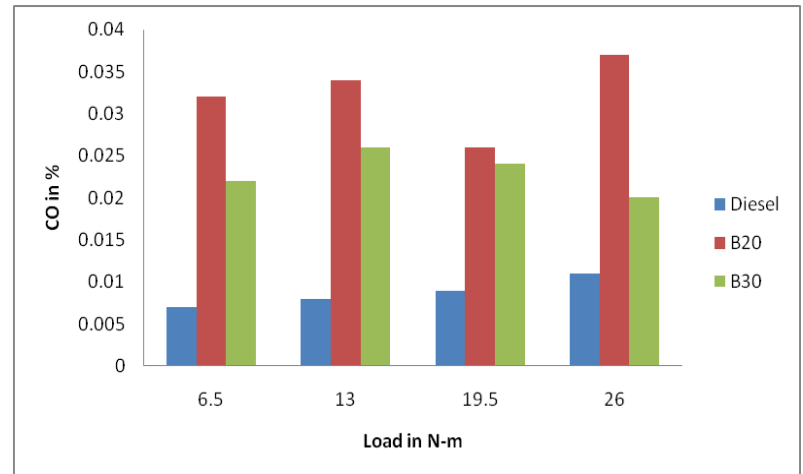

Chart -12: Load v/s Carbon monoxide for $\mathrm{CR}=20.1$, $\mathrm{IP}=300 \mathrm{bar}$.

\subsection{Hydrocarbon Emission}

The variation of hydrocarbon emission with different load for diesel and different bio-diesel blends are as shown in charts $13,14,15 \& 16$. It can be seen in the charts that HC emission is lower for all the blends only at partial loading conditions, but the same has been increased at higher loading conditions. This is because of less time for the reaction and at higher loads more fuel is injected and hence the fuel air mixture will become lean. This experiences less oxygen for combustion. It is also observed from the charts that, bio-diesel blends give relatively higher $\mathrm{HC}$ as compared to the diesel. It is also observed that for both injection pressure of 250 and 300bar at compression ratio of 20.1, blend B20 has less hydrocarbon emissions.

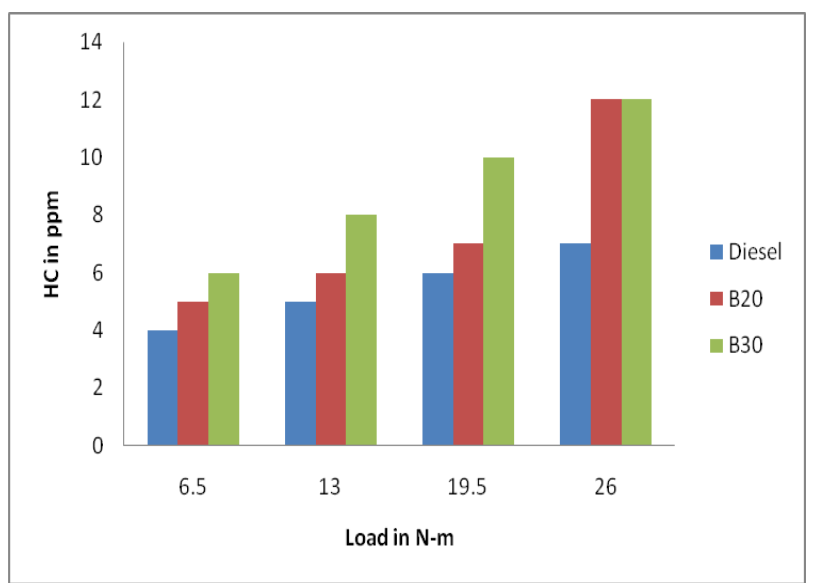

Chart -13: Load v/s Hydrocarbon for $\mathrm{CR}=17.5$, IP=250bar.

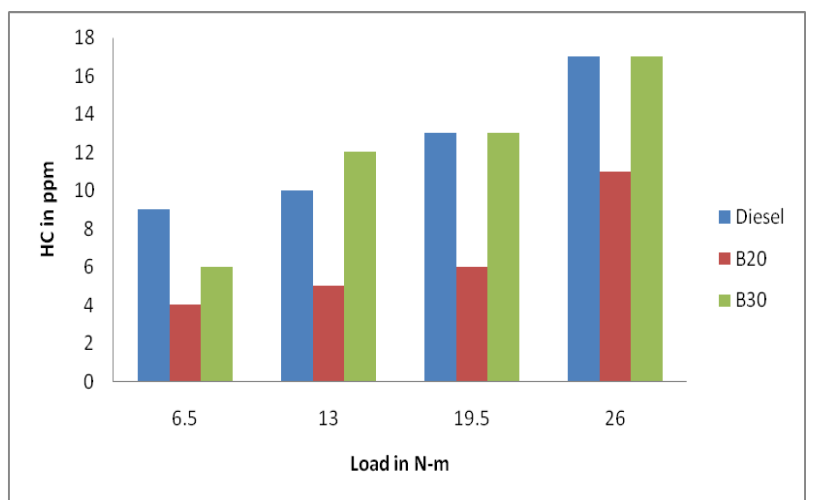

Chart -14: Load v/s Hydrocarbon for $\mathrm{CR}=17.5$, IP=300bar. 


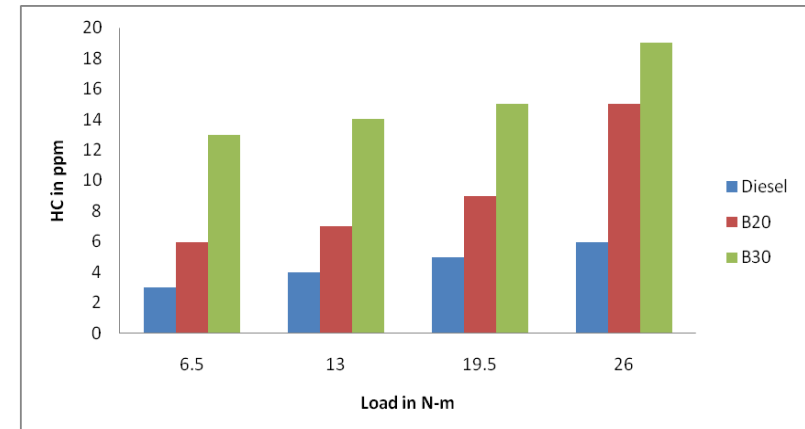

Chart -15: Load v/s Hydrocarbon for $\mathrm{CR}=20.1$, IP=250bar.

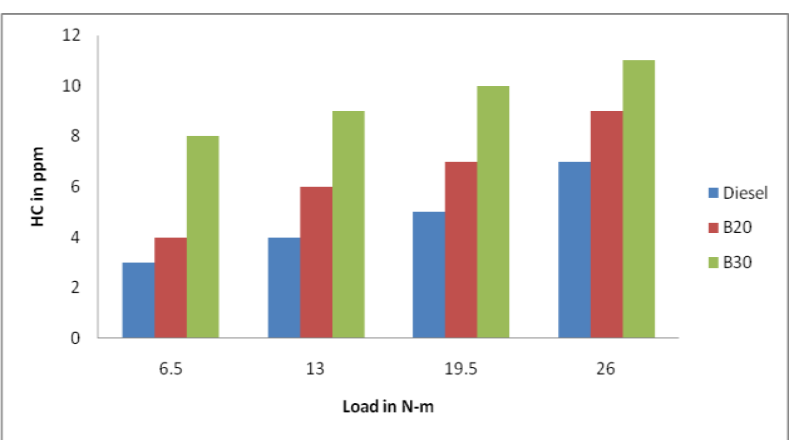

Chart -16: Load v/s Hydrocarbon for $\mathrm{CR}=20.1$, IP=300bar.

\subsection{Nitrogen Oxide}

Variation of nitrogen oxides for CR-17.5, 20.1 and injection pressure at 250bar and 300bar with different load for different fuel blends are shown in charts respectively. NOx emissions are the major and direct indication of combustion temperature. There are many reasons for rising in combustion temperature like, Misfire, longer combustion duration etc. the major effect of NOx emission are respiratory problems such as coughing, asthma, etc.

The above emissions are attained in bio-diesel combustion very rapidly as compared to neat diesel at lower injection pressures of 250 bar. Hence, NOx formations for bio-diesel blends are always greater than neat diesel at lower injection pressure. It can be observed from charts that at high output conditions, there will be higher peak temperatures, the NOx values are likely higher for diesel-bio-diesel blends. As the injection pressure increases the emissions are reduced for bio diesel blends. It can be observed from the graphs that at $\mathrm{IP}=300$ bar the $\mathrm{NO}_{\mathrm{X}}$ emissions are lower than diesel at all different loads.

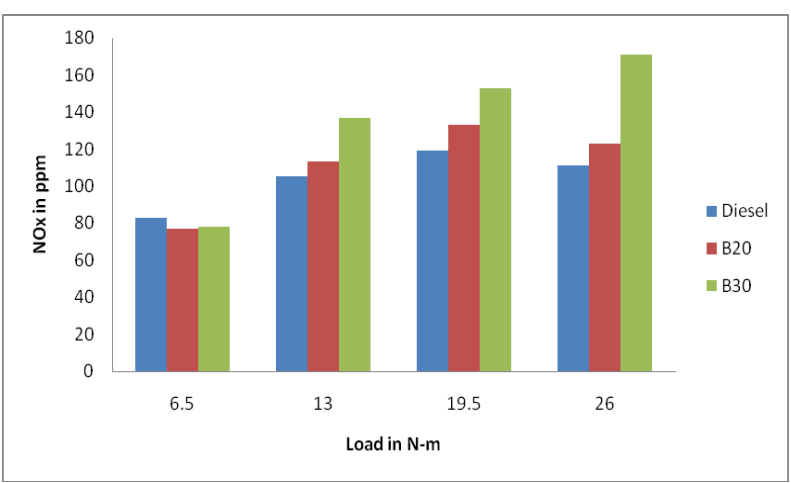

Chart -17: $\mathrm{Load}$ v/s $\mathrm{NO}_{\mathrm{X}}$ for $\mathrm{CR}=17.5, \mathrm{IP}=250 \mathrm{bar}$.

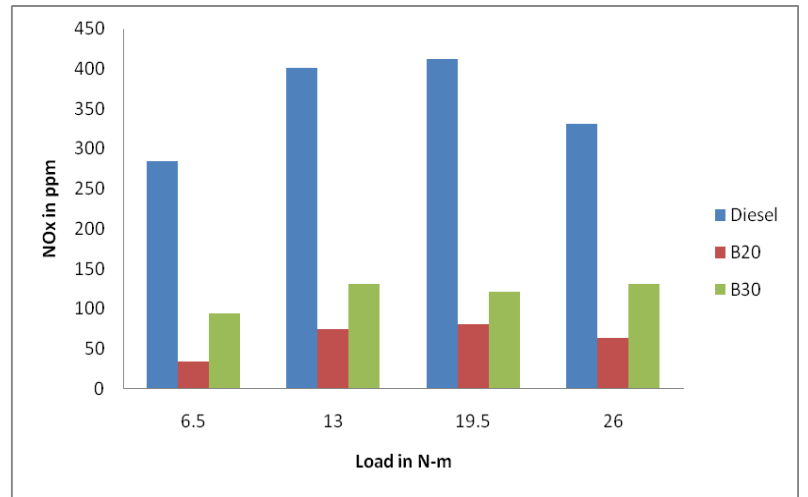

Chart -18: $\mathrm{Load} v / \mathrm{NO}_{\mathrm{X}}$ for $\mathrm{CR}=17.5, \mathrm{IP}=300 \mathrm{bar}$.

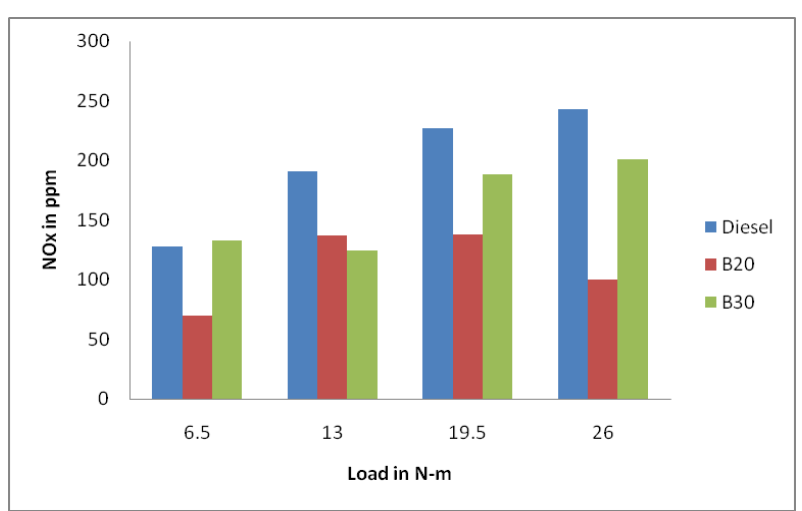

Chart -19: Load v/s $\mathrm{NO}_{\mathrm{X}}$ for $\mathrm{CR}=20.1, \mathrm{IP}=250 \mathrm{bar}$.

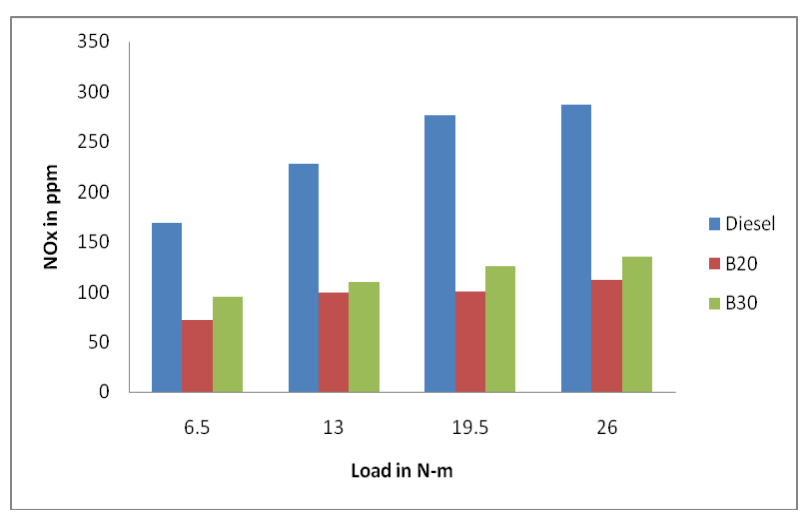

Chart -20: $\mathrm{Load}$ v/s $\mathrm{NO}_{\mathrm{X}}$ for $\mathrm{CR}=20.1, \mathrm{IP}=300 \mathrm{bar}$.

\section{CONCLUSIONS}

The present investigation evaluates the production from sodium hydroxide catalyst, performance and emission characteristics of fish oil bio-diesel compared with neat diesel in a diesel engine under varying injection pressure, load compression ratio and injection pressure. The following conclusions were drawn based on experimental study.

In comparison with the diesel, fish oil bio-diesel shows higher fuel consumption rate, kinematic viscosity, brake fuel consumption. Hence biodiesel produced from fish can be regarded as an best alternative to diesel fuel.

The B30 shows good brake thermal efficiency in comparison with diesel fuel. A little increase in fuel consumption is often observed due to increase in delay period because of high flash point. 
At higher loads engine suffers from nearly 1 to $1.5 \%$ brake thermal loss for all blends.

$>$ Most of the exhaust pollutants such as $\mathrm{CO}, \mathrm{CO}_{2}$ and $\mathrm{HC}$ are reduced with the use of bio-diesel and the blend as compared to neat diesel. But $\mathrm{NO}_{\mathrm{x}}$ emissions increase when fuelled with bio-diesel fuel blends as compared to conventional diesel fuel. This is one of the major limitations of fish oil.

$>$ The exhaust gas temperature increases by increasing the blends as compared to neat diesel due to different characteristics of the diesel and bio-diesel.

> Among all the blends, B-30 gives the improved performance and emission characteristics

$>$ In terms of fuel properties and exhaust emission characteristics, fish oil bio-diesel can be regarded as an alternative to diesel fuel.

$>$ It is found that the cost of fish oil biodiesel is less compared to commercially available diesel fuel including all the byproducts cost of fish oil.

\section{REFERENCES}

[1]. Edwin GeoVaruel, et al. Experimental analysis of biofuel as an alternative fuel for diesel engines. Applied Energy 94 (2012) 224-231.

[2]. Araya Ken, et al. Diesel engine performance with sunflower oil and fish oil. J Senshu University Hokkaido (Nat Sci) 1987;20:137-54.

[3]. Hulya C. Commercial fish oil, vol. 3. Cilt: Trakya Universities Bilimsel; 2002. Nos. 1-6.

[4]. J.F. Costa, M.F. Almeida, M.C.M. Alvim-Ferraz, J.M. Dias, Biodiesel production using oil from fish canning industry wastes. Energy Conversion and Management 74 (2013) 17-23

[5]. Sharanappa Godiganur , Ch. Suryanarayana Murthy, Rana Prathap Reddy. .Performance and emission characteristics of a Kirloskar HA394 diesel engine operated on fish oil methyl esters. Renewable Energy 35 (2010) 355359.

[6]. Rasim Behcet, Recep Yumrutas , Hasan Oktay, Effects of fuels produced from fish and cooking oils on performance and emissions of a diesel engine. Energy (2014) 1 to 11.

[7]. Cherung-Yuan Lin, Rong-ji Li, "Engine performance and emission characteristics of marine fish-oil bio-diesel produced from the discarded parts of marine fish" fuel processing technology 90 (2009) 883-888

[8]. Rasim Behçet, "Performance and emission study of waste anchovy fish bio-diesel in a diesel engine" fuel processing technology 92 (2011) 1187-1194.

[9]. GVNSR Ratnakara Rao, H.W Wang, H.Y. Chen, L.B. Zhou and D.m Jiang, "study of combustion characteristics of a compression ignition engine with dimethyl ether," Proc Instn Mech engrs, vol 213, pp. 1877-1884, 2009

[10]. Basavaraj T, Reddy NRP. Effect of injection pressure on engine performance and emissions of diesel engine with esterified non-edible vegetable oil (pongamia methyl ester) and blend with diesel. SAE International; 2004.
[11]. Ramdas AS, Jayraj S, Muralidharan C. Use of vegetable oils as Internal combustion engines fuels -A review Renewable Energy 2004;29:729-42.

[12]. Rosca Radu, "Exhaust Emission \& Performance of Diesel Engines with Bio Diesel as Fuef'. Fuel 1998, 77, pp 1389-1391.

[13]. Fish oil \& biodiesel in the park, Steigers Corporation, Alaska Energy Authority and The National Park Service. Available from: www.akenergyauthority.org.

[14]. Atabani AE, Mahlia TMI, Masjuki HH, Badruddin IA, Yussof HW, Chong WT, et al. A comparative evaluation of physical and chemical properties of biodiesel synthesized from edible and non-edible oils and study on the effect of biodiesel blending. Energy 2013;58:296e304.

[15]. Behçet R. Performance and emission study of waste anchovy fish biodiesel in a diesel engine. Fuel Process Technol 2011;92(6):1187e94.

[16]. Ozsezen AN, Canakci M. Performance and combustion in a direct injection diesel engine used waste palm and canola oil methyl esters as a fuel, 24(2).Gazi University Faculty of Engineering and Architecture; 2009. pp. $275 \mathrm{e} 84$.

[17]. Agarwal Sanjeev Garg AK. Characterization and utilization of biodiesel as an alternative fuels for diesel engines. Consultative workshop in scientific strategies for production of non-edible oils for use as bio-fuels, Organized by Jagadguru Sri Shivarathreeshwara Academy of Technical Education in Bangalore on 6-7 September 2003.

[18]. Raheman H, et al. Performance of compression ignition engine with Mahua (Madhuca indica) biodiesel. Fuel 2007;86:2568-73. Elsevier.

[19]. Raheman H, et al. Diesel engine emissions and performance from blends of Karanja methyl ester and diesel. Biomass and Bioenergy 2004;27:393-7. Elsevier.

[20]. Jaichander S, Annamalai K (2012) Performance and exhaust emission analysis on pongamia biodiesel with different open combustion chambers in a DI diesel engine. Journal of scientific and industrial research 71: 487-491.

[21]. Agarwal Sanjeev Garg AK. Characterization and utilization of biodiesel as an alternative fuels for diesel engines. Consultative workshop in scientific strategies for production of non-edible oils for use as bio-fuels, Organized by Jagadguru Sri Shivarathreeshwara Academy of Technical Education in Bangalore on 6-7 September 2003.

[22]. Pedro J. García-Moreno a, ${ }^{*}$, Mohriam Khanum b, Antonio Guadix a, Emilia M. Guadix . Optimization of biodiesel production from waste fish oil, Renewable Energy 68 (2014) 618e624

[23]. Dip-Ing Jose N Carrinco, MAN B\&W do Brasil. Green power from diesel engines burning biological oils and recycled fat, Paper presented at the Rio5-world climate \& energy international congress, Rio de Joneiro, Brazil; February 17, 2005. 


\section{BIOGRAPHIES}

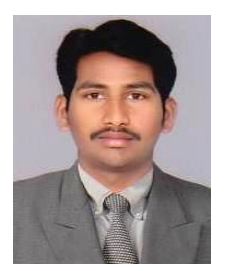

Prof. Keerthi Kumar N, Presently working as Assistant Professor of Mechanical Department at BMS Institute of Technology, Bangalore. Affiliated to Viswesvarahia Technological University, Belgavi, Karnataka. He has 7 years of teaching experience and pursuing Ph.D in the area of IC Engines.

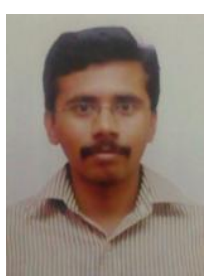

Prof B. Yogesh, Presently working as Assistant Professor in the Dept of Mechanical Engineering, PNS Institute of Technology, Bangalore. Affiliated to Viswesvarahia Technological University, Belgavi, Karnataka. He is having 3 years of teaching experience.

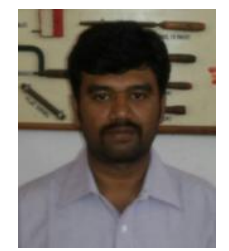

Prof Shankar Nag G L, Assistant Professor, in the department of Mechanical Engineering, Sri Siddhartha Institute of Technology, Tumkur. $\mathrm{He}$ is having 10 years of teaching experience and his area of interest is IC engines, Heat pipe. 